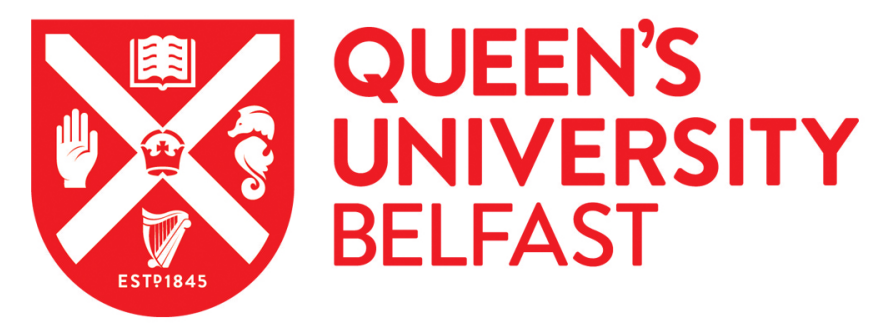

\title{
Functional response quantifies microplastic uptake by a widespread African fish species
}

Mbedzi, R., Dalu, T., Wasserman, R. J., Murungweni, F., \& Cuthbert, R. (2019). Functional response quantifies microplastic uptake by a widespread African fish species. Science of the Total Environment.

Published in:

Science of the Total Environment

Document Version:

Peer reviewed version

Queen's University Belfast - Research Portal:

Link to publication record in Queen's University Belfast Research Portal

Publisher rights

(C) 2019 Elsevier B. V.

This manuscript version is made available under the CC-BY-NC-ND 4.0 license http://creativecommons.org/licenses/by-nc-nd/4.0/,which permits distribution and reproduction for non-commercial purposes, provided the author and source are cited.

\section{General rights}

Copyright for the publications made accessible via the Queen's University Belfast Research Portal is retained by the author(s) and / or other copyright owners and it is a condition of accessing these publications that users recognise and abide by the legal requirements associated with these rights.

Take down policy

The Research Portal is Queen's institutional repository that provides access to Queen's research output. Every effort has been made to ensure that content in the Research Portal does not infringe any person's rights, or applicable UK laws. If you discover content in the Research Portal that you believe breaches copyright or violates any law, please contact openaccess@qub.ac.uk. 


\section{Journal Pre-proofs}

Short communication

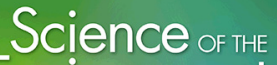

Total Environment

Functional response quantifies microplastic uptake by a widespread African fish species

Rendani Mbedzi, Tatenda Dalu, Ryan J Wasserman, Florence Murungweni, Ross N Cuthbert

PII:

S0048-9697(19)34513-9

DOI: https://doi.org/10.1016/j.scitotenv.2019.134522

Reference: $\quad$ STOTEN 134522

To appear in: $\quad$ Science of the Total Environment

Received Date: $\quad 25$ July 2019

Revised Date: $\quad 16$ September 2019

Accepted Date: $\quad 16$ September 2019

Please cite this article as: R. Mbedzi, T. Dalu, R.J. Wasserman, F. Murungweni, R.N. Cuthbert, Functional response quantifies microplastic uptake by a widespread African fish species, Science of the Total Environment (2019), doi: https://doi.org/10.1016/j.scitotenv.2019.134522

This is a PDF file of an article that has undergone enhancements after acceptance, such as the addition of a cover page and metadata, and formatting for readability, but it is not yet the definitive version of record. This version will undergo additional copyediting, typesetting and review before it is published in its final form, but we are providing this version to give early visibility of the article. Please note that, during the production process, errors may be discovered which could affect the content, and all legal disclaimers that apply to the journal pertain.

(c) 2019 Elsevier B.V. All rights reserved. 
Functional response quantifies microplastic uptake by a widespread African fish species

Rendani Mbedzi ${ }^{\text {a, }}{ }^{+}$, Tatenda Dalu ${ }^{\text {a, }}{ }^{+}$, Ryan J Wasserman ${ }^{\text {b }}$, Florence Murungweni ${ }^{\text {a }}$, Ross N Cuthbert $\mathrm{c}^{*}$

a Aquatic Systems Research Group, Department of Ecology and Resource Management, University of Venda, Thohoyandou 0950, South Africa

${ }^{\mathrm{b}}$ Department of Biological Science and Biotechnology, Botswana International University of Science and Technology, Palapye, Botswana

c School of Biological Sciences, 19 Chlorine Gardens, Queen's University Belfast, Belfast BT9 5DL, Northern Ireland, United Kingdom of Great Britain and Northern Ireland

*Corresponding author-email address:rcuthbert03@qub.ac.uk

${ }^{+}$Equal contributors

Functional response quantifies microplastic uptake by a widespread African fish species

Rendani Mbedzi ${ }^{\text {a, }}{ }^{+}$, Tatenda Dalu ${ }^{\text {a, }}{ }^{+}$, Ryan J Wasserman ${ }^{\text {b }}$, Florence Murungweni ${ }^{\text {a }}$, Ross N Cuthbert c,*

a Aquatic Systems Research Group, Department of Ecology and Resource Management, University of Venda, Thohoyandou 0950, South Africa

b Department of Biological Science and Biotechnology, Botswana International University of Science and Technology, Palapye, Botswana

c School of Biological Sciences, 19 Chlorine Gardens, Queen's University Belfast, Belfast BT9 5DL, Northern Ireland, United Kingdom of Great Britain and Northern Ireland 
*Corresponding author-email address: rcuthbert03@qub.ac.uk

${ }^{+}$Equal contributors 


\begin{abstract}
Ecological impacts of microplastic remain poorly understood, despite their ubiquity across all habitat types globally. Microplastic concentrations vary significantly across spatiotemporal gradients, however we lack quantitative methodologies to predict species-level responses to differential environmental concentrations. In the present study, we expose a key species, the banded tilapia Tilapia sparrmanii Smith, 1940, to different concentrations of microplastic particles. We apply and develop the functional response approach for quantifications of microplastic uptake by the fish across different environmental densities. Tilapia consumed microplastic even when relatively rare in their environment, and consumption rates related negatively to concentrations supplied, conducive with a saturating Type II (i.e., inverselydensity-dependent) functional response. Attack rate (i.e., search efficiency), handling time and maximum feeding rate estimates towards microplastic were estimated, providing key information on feeding behaviour in relation to exposure concentrations. We propose the utility of functional response approaches for predictive quantifications of microplastic uptake rates. In turn, this can better-link laboratory exposure studies to environmental concentrations which are known to cause ecological impact, and provide a means of comparing uptakes among species and across environmental contexts.
\end{abstract}

Keywords: attack rate; handling time; pollution; freshwaters; consumer-resource; polyethylene 


\section{Introduction}

Microplastic $(<5 \mathrm{~mm}$ in size) pollution continues to proliferate across all habitat types and regions globally (Mason et al., 2018; Wagner and Lambert, 2018). Principally driven by the production of artificial plastic materials for human use (Cole et al., 2011), primary (i.e., via direct microplastic release) and secondary (i.e., via macroplastic degradation) origin microplastic enters the environment in a variety of shapes, sizes and densities (Rocha-Santos and Duarte, 2014), with ecosystem ramifications mostly unknown. Enormous quantities of microplastic are released into the environment through household wastewaters (Mason et al., 2016; Wagner and Lambert, 2018), with many particles subsequently transported via riverine systems into seas or lakes, where high concentrations accrue (Erieksen et al. 2013; Fischer et al., 2016; Su et al., 2016). Whilst microplastics have exerted negative ecological impacts on marine ecosystem biota, such as increased mortality (Reichert et al., 2018) and decreased reproduction (Cole et al., 2015), knowledge concerning the impacts of microplastic on freshwater biota remains rudimentary, despite the particular vulnerability of freshwaters to environmental change (Al-Jaibachi et al., 2018; Blettler et al., 2018; Provencher et al., 2018; Cuthbert et al., 2019a; Windsor et al., 2019).

Laboratory-based exposure trials are routinely used to examine the effects of microplastic on flora and fauna, although such studies have recently come under scrutiny for using excessive, environmentally-unrealistic concentrations (Cunningham and Sigwart, 2019). Nevertheless, concentrations of microplastic in aquatic environments are known to be highly variable spatiotemporally (Hurley et al., 2018; Tibbetts et al., 2018; Nel et al., 2018), and therefore uptake of microplastic by biota may vary rapidly over their range in aquatic ecosystems. In turn, impacts of microplastic uptake on organisms may vary substantially owing to potential density-dependent effects (Cuthbert et al., 2019a). Yet, there is currently a lack of 
understanding of how uptake rates by biota respond to differential environmental microplastic concentrations, hampering predictive quantifications of how uptake rates, and thus their ecological impact, relate to environmental heterogeneity in microplastic pollution concentrations.

Functional responses quantify resource use as a function of resource density (Holling, 1959). Whilst functional responses have been widely used to quantify the nature of consumerresource interactions in many ecological fields (e.g., Abrams 1982; Cuthbert et al., 2019b), applications are lacking for quantifications of direct microplastic uptake by organisms (but see Woods et al., 2018). Three forms of functional responses are commonly described: the density-independent linear Type I response; inversely density-dependent hyperbolic Type II response, where consumption rates are high at low densities, and; positively densitydependent Type III response, which is sigmoidal due to low consumption rates at low densities (Hassell, 1978). In theory, Type II functional responses are destabilising for resources (e.g., prey), owing to a lack of low density refuge. By extension, in a microplastic uptake context, a Type II functional response may be indicative of high consumption rates even under low environmental concentrations.

In the present study, we therefore employ a functional response approach to quantify the density-dependence of microplastic uptake by the banded tilapia Tilapia sparrmanii Smith, 1940, which is a widespread and key species in warm freshwater habitats of southern Africa. This species has been introduced to many freshwater basins, and is distributed extensively outside of its native range (Ellender and Weyl, 2014). Banded tilapia readily consumes animal prey, however its diet is also known to include plant material (Zengeya and Marshall 2007; Marshall 2011). Given its broad diet and extensive distribution, banded tilapia 
represent a suitable model species for examination of microplastic uptake. We hypothesise that microplastic uptake by juvenile stages of the fish will relate positively to environmental microplastic concentrations. Further, we expect that tilapia will uptake microplastic even when present at relatively low densities in aquatic environments.

Collection of captive-bred fish and all experiments were carried out in compliance with the ethical clearance approved by the University of Venda Research Committee (no. SES/18/ERM/10/1009), South Africa.

\section{Materials and methods}

\section{Experimental design and analysis}

Banded tilapia, Tilapia sparrmanii Smith, 1840 were supplied from Netshituni Fishery

Project Phiphidi, Vhembe District, South Africa. All fish were transported to the Department of Ecology and Resource Management, University of Venda, Thohoyandou and were housed in $30 \mathrm{~L}$ buckets with continuously aerated water $\left(23.2 \pm 0.3{ }^{\circ} \mathrm{C} ; 12: 12\right.$ light:dark photoperiod). Fish were allowed to acclimate to the system for at least 48 hours prior to use in microplastic trials. Experiments were conducted in individual $10 \mathrm{~L}$ buckets filled with $4 \mathrm{~L}$ of filtered (63 $\mu \mathrm{m}$ mesh sieve) and matured tap water. Banded tilapia were size matched with respect to standard length (SL $\pm \mathrm{SD}: 32.4 \pm 2.1 \mathrm{~mm}$ ) and were starved for 30 hours prior to the experiment to standardise hunger levels. Fish were randomly selected two hours prior to use and placed individually in $10 \mathrm{~L}$ white plastic buckets to settle. After the acclimatisation period, fish were presented with microplastic (i.e., ultra-high molecular weight, surfacemodified multi-coloured polyethylene powder, $125 \mu \mathrm{m}$ particle size (Sigma-Aldrich, UK)) at four densities $\left(0.05 \mathrm{~g}\left(\sim 155\right.\right.$ particles/39 particles $\left.\mathrm{L}^{-1}\right), 0.1 \mathrm{~g}\left(\sim 309\right.$ particles/77 particles $\left.\mathrm{L}^{-1}\right)$, $0.5 \mathrm{~g}\left(\sim 1545\right.$ particles/386 particles $\left.\mathrm{L}^{-1}\right), 1 \mathrm{~g}\left(\sim 3090\right.$ particles/773 particles $\left.\left.\mathrm{L}^{-1}\right)\right)$, each mixed 
with $2 \mathrm{~g}$ of tilapia fish food (Rainbow Kingdom, Louis Trichardt) and with five replicates per density. Therefore, 25 individual fish were used in total for the experiment. To initiate the feeding period, fish flakes were added evenly to the surface of the water with the allocated microplastic treatments. Whilst recent studies have been criticised for using unrealistic microplastic concentrations (see Cunningham and Sigwart, 2019), quantities used in the present study span both 'low' (i.e. < 100 particles L-1) and 'high' (i.e. > 100 particles L-1) dosages, with 100 particles $\mathrm{L}^{-1}$ regarded as the highest measured environmental concentration (Burns and Boxall, 2018). Microplastic treatment presentations were fully crossed and randomised so that all combinations were trialled simultaneously. Feeding trials were run for 4 hours and were initiated at midday, after which microplastic consumption was examined. Controls were run simultaneously and consisted of five replicates in the absence of microplastic, with only fish food.

At the end of the experiment, all fish were euthanised by immersion in $40 \mathrm{mg} \mathrm{L}^{-1}$ of clove oil and fixed in $99 \%$ ethanol for stomach contents analysis to determine the numbers of microplastic eaten. The entire gut was removed from each fish for quantification of microplastic uptake, using new petri dishes that were rinsed with distilled water for each individual. Laboratory blanks were used to ensure that there were no microplastic particles in the distilled water. As the microplastics are relatively resistant to digestion, individual consumption within fish was inferred by quantifying numbers of microplastic in stomach contents under a Carl Zeiss Stemi dissecting microscope (Carl Zeiss MicroImaging GmbH, Göttingen). Owing to the relatively large size and thus high detectability of experimental microplastic particles, it was not necessary to use digestion on fish and we did not expect microplastic to be lodged in the gut lining. 


\section{Data analysis}

Differences in fish lengths (mm; integers) among microplastic treatments (5 levels) were examined using generalised linear models (GLMs) assuming Poisson distributions of error with log links. A nested likelihood ratio test was used to infer the treatment effect size and significance level. Similarly, raw microplastic consumption (counts) was analysed using Poisson GLMs according to microplastics treatment (4 levels, excluding microplastic-free control). Residuals were examined in each model to ensure there was no significant evidence for overdispersion, allowing a Poisson rather than e.g. quasi-Poisson error family to be used.

Functional response analyses followed two stages. First, logistic regression was used to analyse proportional microplastic consumption (counts) as a function of initial microplastic abundance (i.e., density; continuous predictor) in order to categorise the functional response (i.e., into Types I, III, III). From this regression, a significantly negative first order term indicates a Type II functional response (Juliano, 2001). Second, functional responses were modelled using Rogers' random predator equation owing to the non-replacement of microplastic particles during the experiment (Rogers, 1972):

$$
N_{e}=N_{0}\left(1-\exp \left(a\left(N_{e} h-T\right)\right)\right)
$$

where $N_{e}$ is the number of microplastic particles consumed, $N_{0}$ is the initial density of particles, $a$ is the attack rate, $h$ is the handling time and $T$ is the experiment duration (fixed at 1, i.e., 4 hours). Attack rates corresponds to the functional response curve slope (i.e., area or volume cleared per unit time by fish), whilst the handling time, inversely, corresponds to the functional response asymptote (i.e., fish maximum feeding rate). The Lambert $\mathrm{W}$ function was used to allow for model fitting, owing to the recursive nature of the random predator equation (Bolker, 2008). A non-parametric bootstrapping procedure $(n=2000)$ was followed 
to generate $95 \%$ confidence intervals (CIs) around the functional response curve (Pritchard et al., 2017). In all analyses, significance was inferred at a threshold of $p<0.05$.

\section{Results}

The length of fish used in the experiment did not differ significantly depending on microplastic exposure group (GLM: $\left.\chi^{2}=0.29, \mathrm{df}=4, p=0.99\right)$. Therefore, size-related differences likely did not significantly alter propensities for microplastic consumption by fish. No microplastic particles were consumed in control fish, and it was thus unnecessary to adjust consumption to account for any background levels of plastics. Microplastic was found in $100 \%$ of exposed tilapia, and counts tended to increase slightly with greater exposure concentrations (Figure 1). Nevertheless, there were no statistically clear differences in microplastic consumption among exposure concentrations (GLM: $\chi^{2}=4.57, \mathrm{df}=3, p=0.21$ ), with fish consistently consuming particles even when relatively sparse in the environment.

The proportion of microplastic consumed (i.e., numbers eaten relative to numbers remaining) was significantly negatively related to the initial experimental particle density (GLM: linear coefficient $=0.0009, z=19.55, p<0.001)$. Therefore, fish exhibited significant evidence for a hyperbolic Type II functional response, characterised by high proportional consumption rates at low densities (Figure 2). This enabled functional response attack rate $(a)$ and handling time $(h)$ parameters to be estimated (random predator equation: $a=0.63, z=1.88, p=0.06 ; h$ $=0.04, z=14.52, p<0.001)$. Accordingly, fish exhibited maximum consumption rates $(1 / h$; i.e., functional response asymptote) of approximately 25 particles over the 4 hour experimental period (Figure 2). 


\section{Discussion}

The present study demonstrates the potential for Tilapia sparrmanii to uptake microplastic across a gradient of environmental concentrations. Tilapia were found to uptake microplastic even when relatively rare in their aquatic environment, with increasing concentrations having a positive but statistically unclear effect on uptake levels. Under higher concentrations than tested in the present study, microplastic particles have been shown to accrue across all tissues of freshwater tilapia following consumption (Ding et al., 2018). In turn, adverse impacts on juvenile fish stages have been reported following exposure to concentrations aligned with the lowest levels in this study, such as anemia (e.g., Hamed et al., 2019). Further, uptake of microplastic has been shown to interact with, and potentially alter, toxicity levels of other pollutants upon tilapia (Zhang et al., 2019). Therefore, the quantified propensity for $T$. sparrmanii to uptake microplastic in the present study may drive biotic impacts even under relatively low environmental concentrations, with the present study spanning both low and high dosages from empirical measurements (Cunningham and Sigwart, 2019).

Microplastic uptake by T. sparrmanii exhibited significant non-linear density-dependence in the present study, with uptake rates falling asymptotically with increasing environmental concentrations. This aligns with a Type II functional response, where proportional uptake rates are highest under low environmental densities (i.e., concentrations) (Holling, 1959). This suggests that $T$. sparrmanii actively uptakes microplastic even where relatively rare in the environment. Functional responses offer great utility in quantifications of resource uptake under different densities (e.g., Cuthbert et al., 2019b), and the approach thus lends itself to microplastic studies where density-dependences of uptake may be deciphered. In turn, feeding behaviours may be related against microplastic concentrations documented to caused impact. Here, the functional response approach returned attack rate (i.e., search efficiency) 
and handling time parameters towards microplastic by T. sparrmanii. In this context, the attack rate corresponds to the volume cleared per unit time by fish (i.e., curve initial slope), whilst the handling time is the time taken to capture, consume and digest. Inversely, the handling time estimate enabled maximum feeding rates (i.e., curve asymptote) of microplastic to be calculated for $T$. sparrmanii, providing important quantitative information relating to the propensity for this species to uptake microplastic over time. Whilst not evidenced in the present study, further studies should examine excretion rates of microplastic, and how these may influence uptake, retainment and distribution in organisms under different experimental durations

Just as functional responses can be used to quantify interaction strengths in consumerresource (e.g., predator-prey) systems (Kalinoski and DeLong, 2016), we propose the use of functional responses in quantifications of microplastic uptake rates. Functional responses can be subsequently compared among species or across environmental contexts to better understand key drivers which may alter uptake rates (Cuthbert et al., 2019b). Further, differences in uptake rates across microplastic polymer types and sizes could be examined using a functional response approach. Ultimately, understandings of species-level feeding responses to different environmental concentrations will assist in our understanding of microplastic impacts, and help to better-link laboratory exposure studies to real-world concentrations.

\section{Acknowledgements}

Financial support for this study was granted by the National Research Foundation of South Africa Thuthuka (NRF, UID: 117700) and University of Venda Niche grants (SES/18/ERM/10) to TD. Any opinions, findings, conclusions or recommendations expressed 
in this material are those of the authors, and the NRF does not accept any liability in this regard. RNC acknowledges funding from the Department for the Economy, Northern Ireland. We thank Thendo Mutshekwa and Khuthadzo Mavhunga for assisting with the experimental set-up.

\section{References}

Abrams, P. A. (1982). Functional responses of optimal foragers. American Naturalist, 120: (3)382-390.

Al-Jaibachi, R., Cuthbert, R. N. and Callaghan, A. (2018). Up and away: ontogenic transference as a pathway for aerial dispersal of microplastics. Biology Letters, 14: (9)20180479.

Blettler, M.C.M., Abrial, E., Khan, F.R., Sivri, N. and Espinola, S.A. (2018). Freshwater plastic pollution: recognizing research biases and identifying knowledge gaps. Water Research, 143: 416-424.

Burns, E.E. and Boxall, A.B.A. (2018). Microplastics in the aquatic environment: Evidence for or against adverse impacts and major knowledge gaps. Environmental Toxicology and Chemistry, 37: 2776-2796.

Bolker, B. M. (2008). Ecological Models and Data in R. Princeton University Press.

Cole, M., Lindeque, P., Fileman, E., Halsband, C., and Galloway, T. S. (2015). The impact of polystyrene microplastics on feeding, function and fecundity in the marine copepod Calanus helgolandicus. Environmental Science and Technology, 49(2): 1130-1137.

Cole, M., Lindeque, P., Halsband, C. and Galloway, T. S. (2011). Microplastics as contaminants in the marine environment: a review. Marine Pollution Bulletin, 62(12): 2588-97. 
Cunningham, E. M. and Sigwart, J. E. (2019). Environmentally accurate microplastic levels and their absence from exposure studies. Integrative and Comparative Biology, in press.

Cuthbert, R. N., Al-Jaibachi, R., Dalu, T., Dick, J. T. A., and Callaghan, A. (2019a). The influence of microplastics on trophic interaction strengths and oviposition preferences of dipterans. Science of the Total Environment, 651: 2420-2423.

Cuthbert, R. N., Dickey, J. W. E., Coughlan, N. E., Joyce, P. W. S. and Dick, J. T. A. (2019b). The Functional Response Ratio (FRR): advancing comparative metrics for predicting the ecological impacts of invasive alien species. Biological Invasions, 21: $2543-2547$.

Ding, J. N., Zhang, S. S., Razanajatovo, R. M., Zou, H. and Zhu, W. B. (2018). Accumulation, tissue distribution, and biochemical effects of polystyrene microplastics in the freshwater fish red tilapia (Oreochromis niloticus). Environmental Pollution, 238: 1-9.

Ellender, B.R., Weyl, O.L.F. (2014). A review of current knowledge, risk and ecological impacts associated with non-native freshwater fish introductions in South Africa. Aquatic Invasions, 9: 117-132.

Eriksen, M., Mason, S., Wilson, S., Box, C., Zellers, A., Edwards, W., Farley, H. and Amato, S. (2013). Microplastic pollution in the surface waters of the Laurentian Great Lakes. Marine Pollution Bulletin, 77(1-2): 177-182.

Fischer, E. K., Paglialonga, L., Czech, E. and Tamminga, M. (2016). Microplastic pollution in lakes and lake shoreline sediments - a case study on Lake Bolsena and Lake Chiusi (central Italy). Environmental Pollution: 213, 648-657.

Hamed, M., Soliman, H. A. M., Osman, A. G. M. and Sayed, A. E. D. H. (2019). Assessment the effect of exposure to microplastics in Nile Tilapia (Oreochromis niloticus) early juvenile: I. blood biomarkers. Chemosphere, 228: 345-350. 
Hassell, M.P. (1978). The Dynamics of Arthropod Predator-Prey Systems. Princeton University Press.

Holling, C. S. (1959). Some characteristics of simple types of predation and parasitism. Canadian Entomologist, 91(7): 385-398.

Hurley, R., Woodward, J. and Rothwell, J. J. (2018). Microplastic contamination of river beds significantly reduced by catchment-wide flooding. Nature Geoscience, 11(4): 251257.

Juliano, S. A. (2001). Nonlinear curve fitting: predation and functional response curves. Design and Analysis of Ecological Experiments, 2nd edn. (eds. Scheiner, S. M. and Gurevitch, J.), pp. 178-196. Oxford University Press.

Kalinoski, R. M. and DeLong, J. P. (2016). Beyond body mass: how prey traits improve predictions of functional response parameters. Oecologia, 180(2): 543-550.

Mason, S. A., Welch, V. and Neratko, J. (2018). Synthetic polymer contamination in bottled water. Frontiers in Chemistry, 6: 407.

Marshall, B. (2011). The Fishes of Zimbabwe and their Biology. Smithiana Monograph No. 3. South African Institute for Aquatic Biodiversity.

Nel, H. A., Dalu, T. and Wasserman, R. J. (2018). Sinks and sources: Assessing microplastic abundance in river sediment and deposit feeders in an Austral temperate urban river system. Science of the Total Environment, 612: 950-956.

Pritchard, D. W., Paterson, R. B., Bovy, H. C. and Barrios-O’Neill, D. (2017). FRAIR: an R package for fitting and comparing consumer functional responses. Methods in Ecology and Evolution, 8(11): 1528-1534.

Provencher, J.F., Ammendolia, J., Rochman, C.M. and Mallory, M.L. (2018). Assessing plastic debris in aquatic food webs: what we know and don't know about uptake and trophic transfer. Environmental Reviews, in press. 
Reichert, J., Schellenberg, J., Schubert, P. and Wilke, T. (2018). Responses of reef building corals to microplastic exposure. Environmental Pollution, 237: 955-960.

Rocha-Santos, T. and Duarte, A. C. (2014). A critical overview of the analytical approaches to the occurrence, the fate and the behavior of microplastics in the environment. Trends in Analytical Chemistry, 65: 47-53.

Rogers, D. (1972). Random search and insect population models. Journal of Animal Ecology, 41: $369-383$.

Su, L., Xue, Y., Li, L., Yang, D., Kolandhasamy, P., Li, D. and Shi, H. (2016). Microplastics in Taihu Lake, China. Environmental Pollution, 216: 711-719.

Tibbetts, J., Krause, S., Lynch, I., and Sambrook Smith, G. H. (2018). Abundance, distribution, and drivers of microplastic contamination in urban river environments. Water, 10(11): 1597.

Wagner, M. and Lambert, S. (2018). Freshwater microplastics. Cham Switzerland Springer International Publishing.

Windsor, F.M., Tilley, R.M., Tyler, C.R. and Ormerod, S.J. (2019). Microplastic ingestion by riverine macroinvertebrates. Science of the Total Environment, 646: 68-74.

Woods, M.N., Stack, M.E., Fields, D.M., Shaw, S.D. and Matrai, P.A. (2018). Microplastic fiber uptake, ingestion, and egestion rates in the blue mussel (Mytilus edulis). Marine Pollution Bulletin, 137: 638-645.

Zengeya, T.A. and Marshall, B.E. (2007). Trophic interrelationships amongst cichlid fishes in a tropical African reservoir (Lake Chivero, Zimbabwe). Hydrobiologia, 592: 175-182.

Zhang, S. S., Ding, J. N., Razanajatovo, R. M., Jiang, H., Zou, H. and Zou, W. B. (2019). Interactive effects of polystyrene microplastics and roxithromycin on bioaccumulation and biochemical status in the freshwater fish red tilapia (Oreochromis niloticus). Science of the Total Environment, 648: 1431-1439. 


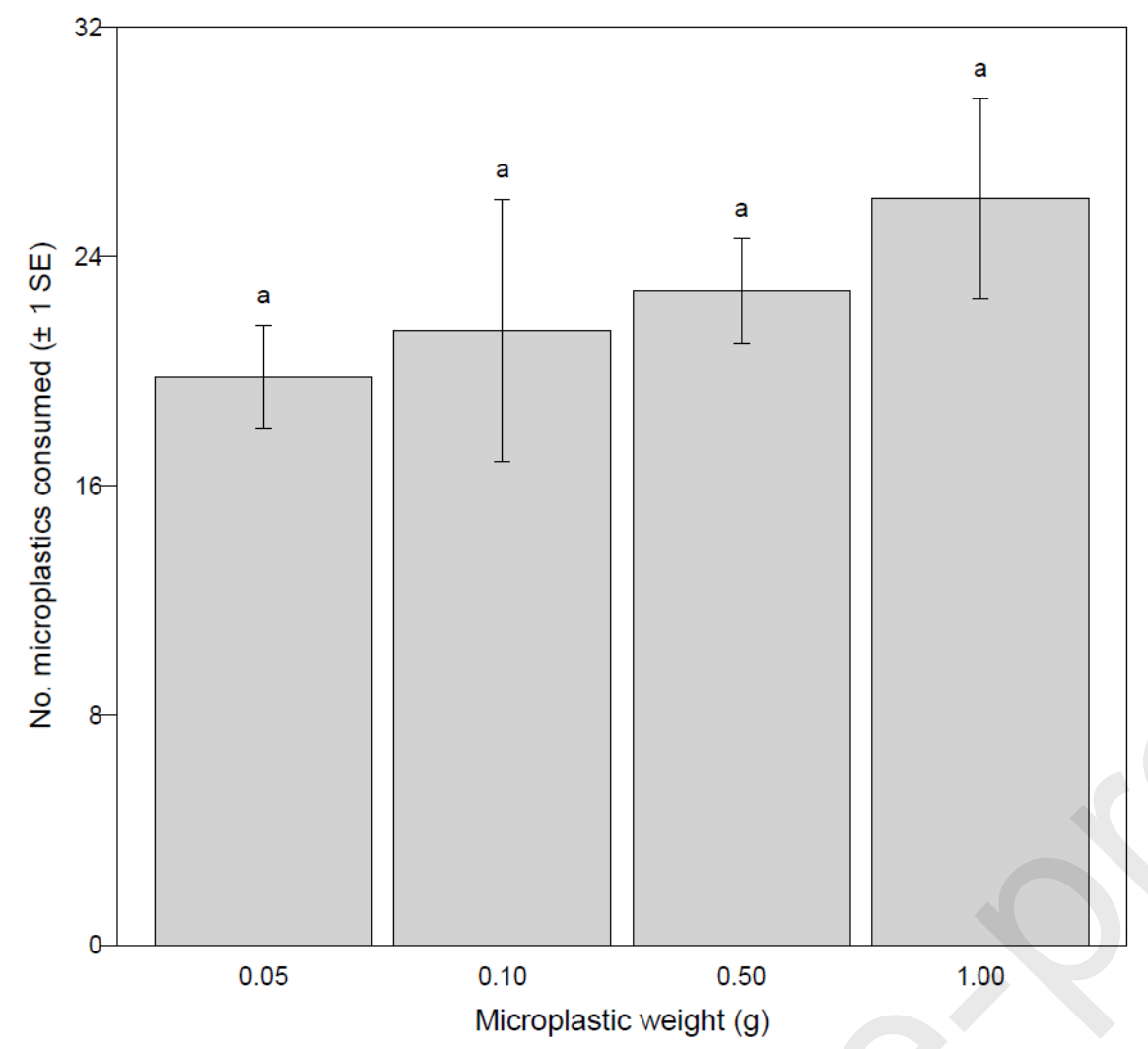

Figure 1. Mean ( $\pm 1 \mathrm{SE})$ numbers of microplastic consumed (i.e., counted in gut) by individual fish among different initial exposure weights $\left(\mathrm{g}^{4} \mathrm{~L}^{-1}\right)$ following 4 hour experimental period. Letters above indicate a lack of significant differences. 


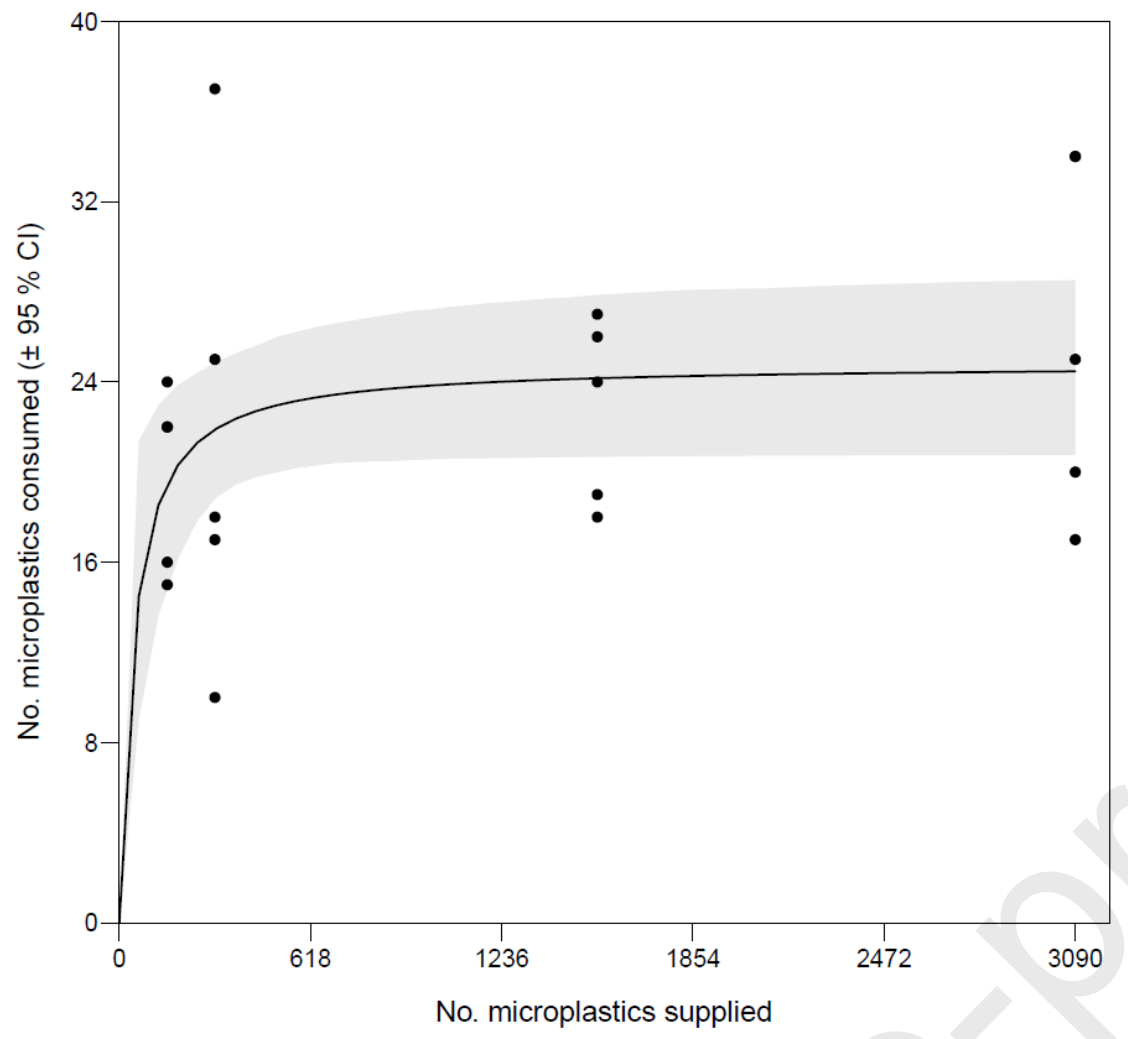

Figure 2. Type II functional response of fish towards microplastics at different exposures (no. particles $4 \mathrm{~L}^{-1}$ ) following 4 hour experimental period. Grey areas are bootstrapped $95 \%$ CIs and points are underlying raw consumption data.

- Banded tilapia Tilapia sparrmanii consumed microplastic in aquatic environment.

- Consumption did not significantly relate to exposure concentration.

- Tilapia exhibited a saturating Type II functional response towards microplastic.

- Functional responses are powerful in microplastic uptake assessments. 